\title{
A cohort study of reproductive and hormonal factors and renal cell cancer risk in women
}

\author{
GC Kabat ${ }^{*, 1}$, SA Navarro Silvera', AB Miller² and TE Rohan' \\ 'Department of Epidemiology and Population Health, Albert Einstein College of Medicine, I 300 Morris Park Avenue, Room I 30 I, NY I046I, USA; \\ ${ }^{2}$ Department of Public Health Sciences, University of Toronto, Toronto, Canada
}

\begin{abstract}
We examined the association of reproductive and hormonal factors with renal cell cancer risk in a cohort study of 89835 Canadian women. Compared with nulliparous women, parous women were at increased risk (hazard ratio (HR) I.78, 95\% confidence interval (Cl) $1.02-3.09$ ), and there was a significant gradient of risk with increasing levels of parity: relative to nulliparous women, women who had $\geqslant 5$ pregnancies lasting 4 months or more had a 2.4 -fold risk $(H R=2.4 \mathrm{I}, 95 \% \mathrm{Cl}=1.27-4.59$, P for trend $0.0 \mathrm{I})$. Ever use of oral contraceptives was associated with a modest reduction in risk. No associations were observed for age at first live birth or use of hormone replacement therapy. The present study provides evidence that high parity may be associated with increased risk of renal cell cancer, and that oral contraceptive use may be associated with reduced risk.

British Journal of Cancer (2007) 96, 845-849. doi: I 0.I038/sj.bjc.6603629 www.bjcancer.com
\end{abstract}

Published online 20 February 2007

(c) 2007 Cancer Research UK

Keywords: kidney neoplasms; cohort; reproductive factors; hormones; smoking; body mass index; parity

Incidence rates of renal cell cancer have been increasing both in the USA and globally since the 1970s (Chow et al, 1999; McLaughlin et al, 2006), and renal cell carcinomas account for approximately $80 \%$ of renal cancers (McLaughlin et al, 2006). While cigarette smoking, obesity, and hypertension are established risk factors for renal cell cancer, few other risk factors have been identified conclusively (Lindblad and Adami, 2002; McLaughlin et al, 2006). Smoking, obesity, and hypertension have been estimated to account for roughly $68 \%$ of renal cancer incidence in women (Benichou et al, 1998), leaving a substantial proportion of this cancer still unexplained.

A number of findings suggest a possible role of reproductive or hormonal factors in renal cell cancer. First, over the past 30 years, incidence rates of renal cell cancer have been increasing more rapidly in women than in men in the USA and the UK (Katz et al, 1994; Chow et al, 1999; Tate et al, 2003), suggesting a possible association with exposure to exogenous hormones. Second, steroid hormone receptors have been found in both normal and cancerous renal cell tissue, suggesting hormonal regulation (Ronchi et al, 1984; Siiteri, 1987; Vugrin, 1987). Third, renal tumours can be induced in experimental animals with diethylstilbestrol and oestradiol (Kirkman, 1959; Reznik-Schuller, 1979; Li and Li, 1990). Finally, obesity, a consistent risk factor for renal cell cancer, is the main source of endogenous exposure to oestrogen in postmenopausal women (Siiteri, 1987).

Only a few studies have examined endocrine factors in relation to renal cell cancer risk (Krieger et al, 1992; McCredie and Stewart, 1992; Cantor et al, 1993; Mellemgaard et al, 1994; Chow et al, 1995;

*Correspondence: Dr GC Kabat; E-mail address: gkabat@aecom.yu.edu Received 13 December 2006; revised 17 January 2007; accepted 19 January 2007; published online 20 February 2007
Lindblad et al, 1995; Gago-Dominguez et al, 1999; McLaughlin and Lipworth, 2000; Lambe et al, 2002; Nicodemus et al, 2004) and their findings have been inconsistent. Only two cohort studies (Lambe et al, 2002; Nicodemus et al, 2004) have addressed the role of reproductive and hormonal factors, but each was limited to two exposures of interest. Given the current lack of data from prospective studies on this topic, we examined the association between reproductive and hormonal factors and renal cell cancer risk in a cohort of Canadian women.

\section{MATERIALS AND METHODS}

\section{Study population}

The study, which has been described in detail elsewhere (Miller et al, 1992), was conducted among participants in the Canadian National Breast Screening Study (NBSS), a randomised controlled trial of screening for breast cancer. A total of 89835 women aged 40-59 years with no history of breast cancer were recruited into the trial between 1980 and 1985. Participating women were randomised to receive either (1) screening with annual mammography, breast physical examination, and instruction on breast self-examination on four or five occasions, or (2) community care after a single breast physical examination and instruction on breast self-examination. The NBSS was approved by the appropriate Institutional Review Boards, and informed consent was obtained from all study participants.

\section{Questionnaires and anthropometric measurements}

At recruitment into the cohort, participants completed selfadministered questionnaires that sought information on demo- 
graphic characteristics, lifestyle factors (including cigarette smoking), menstrual and reproductive history, and use of oral contraceptives and hormone replacement therapy (HRT). Specifically, participants were asked questions about their age at menarche, menopausal status, number of pregnancies lasting greater than 4 months (parity), age at first live birth, and ever use and duration of use of oral contraceptives and of HRT. In addition, height and weight were measured at the initial physical examination.

\section{Ascertainment of incident renal cell cancer cases and deaths}

Incident cases of renal cell cancer and deaths from all causes were ascertained, respectively, by means of computerised record linkages to the Canadian Cancer Database and to the National Mortality Database, both of which are maintained by Statistics Canada. The linkages to the databases yielded data on cancer incidence and mortality to 31 December 2000 for women in Ontario, 31 December 1998 for women in Quebec, and 31 December 1999 for women in other provinces.

\section{Statistical analysis}

Of the 89835 women recruited into the study, we excluded women with prevalent renal cancer at baseline $(n=14)$, leaving 89821 women available for analysis, among whom 199 incident cases of renal cancer were observed. We further excluded 27 cases with cancer of the renal pelvis and a morphology code of transitional cell carcinoma, leaving 172 cases with cancer of the renal parenchyma. For these analyses, study participants were considered at risk from their date of enrolment until the date of diagnosis of their renal cell carcinoma, termination of follow-up (the date to which cancer incidence data were available for women in the corresponding province) or death, whichever occurred first. Cox proportional hazards models (using age as the time scale) were used to estimate hazard ratios (HRs) and 95\% confidence intervals (CIs) for the association between reproductive and hormonal factors and renal cell cancer risk. All multivariate models included terms for body mass index (BMI) $\left(\mathrm{kg} \mathrm{m}^{-2}\right)$ (quintiles), pack-years of smoking (never smokers + five levels), menopausal status at baseline (pre-, peri-, postmenopausal), education (three levels), study centre, and randomisation group (intervention or control in the original clinical trial). Women who reported having regular menstrual periods within the 12 months before baseline or who had had a hysterectomy without bilateral oophorectomy and were less than 45 years of age were classified as premenopausal. Women whose menstrual periods ceased more than 12 months before baseline, those who had had a bilateral oophorectomy, and those who had had a hysterectomy and were over 55 years of age were considered postmenopausal (Rohan et al, 1998). Women whose periods were irregular and those who had a hysterectomy and were between 45 and 55 years old were considered perimenopausal. To test for trends in risk with increasing levels of the exposures of interest, we either assigned the categorical variables (parity) their ordinal number or the category median (age at first live birth, duration of oral contraceptive use, duration of HRT) and then fitted the assigned value of each risk factor as a continuous variable in the risk models. We then evaluated the statistical significance of the corresponding coefficient using the Wald test (Rothman and Greenland, 1998). Tests for interaction were based on comparing the likelihood ratio tests in models with and without the product terms representing the variables of interest. The likelihood ratio test that all of the interaction parameters were 0 was performed by referring $2^{*}$ the absolute difference in the log likelihoods of models with and without interaction terms to the $\chi^{2}$ distribution with degrees of freedom equal to the number of interaction parameters. Use of the life-test procedure in $\mathrm{SAS}^{\mathrm{TM}}$ showed that the proportional hazards assumption was met in this data set. All analyses were performed using SAS version 9 (SAS Institute Cary, NC, USA).

\section{RESULTS}

The average duration of follow-up for cohort members was 16. 4 years (1 474006 person-years). Table 1 shows the baseline characteristics of the study population by case status at the end of follow-up. Briefly, compared to non-cases, renal cell cancer cases were older, had a higher mean BMI, were more likely to have had five or more pregnancies lasting greater than 4 months, were more likely to be postmenopausal, were more likely to be current smokers, and were less likely to have ever used oral contraceptives.

Compared to nulliparous women, parous women had an increased risk of renal cell cancer (multivariate-adjusted HR $1.78,95 \%$ CI 1.02-3.09), and there was a significant gradient with increasing level of parity: relative to nulliparous women, women who had $\geqslant 5$ pregnancies lasting $4+$ months had a 2.4 -fold risk $(\mathrm{HR}=2.41,95 \% \mathrm{CI}=1.27-4.59, P$ for trend $=0.01)($ Table 2$) . \mathrm{A}$ relatively late age at menarche appeared to be associated with a modestly increased risk, and ever use of oral contraceptives was associated with slightly reduced risk. However, these results did not achieve statistical significance, and there was no clear trend with age at menarche or duration of oral contraceptive use. Perimenopausal and postmenopausal women were at increased risk compared to premenopausal women. No associations were seen with age at first live birth or use of HRT.

Both smoking and BMI showed positive dose-response relationships, in line with previous studies. Compared to never smokers, smokers of $40+$ pack-years had a HR of $2.12,95 \% \mathrm{CI}$ 1.21-3.71, $P$ for trend 0.004; compared to the lowest quintile of BMI, women in the highest quintile had a HR of $1.76,95 \%$ CI $1.03-$ 3.03, $P$ for trend 0.02 . Table 3 presents the associations of parity and oral contraceptive use stratified by major known risk factors. The positive association of parity with renal cell cancer was limited to women 50-59 years old at enrolment $(P$ for interaction $=0.11)$ and to never smokers $(P$ for interaction $<0.005)$. For women aged

Table I Baseline characteristics of the study population by outcome

\begin{tabular}{|c|c|c|}
\hline Factor & $\begin{array}{l}\text { Incident renal cell } \\
\text { cancer cases } \\
(n=172)\end{array}$ & $\begin{array}{l}\text { Non-cases } \\
(n=89617)\end{array}$ \\
\hline $\begin{array}{l}\text { Mean age at baseline } \\
\text { (years) }\end{array}$ & $50.7(5.6)$ & $48.5(5.6)$ \\
\hline Mean BMI $\left(\mathrm{kg} \mathrm{m}^{-2}\right)^{\mathrm{a}}$ & $26.1(5.1)$ & $25.1(4.7)$ \\
\hline $\begin{array}{l}\text { Mean age at menarche } \\
\text { (years) }\end{array}$ & $13.0(1.4)$ & $12.8(2.2)$ \\
\hline $\begin{array}{l}\text { Mean age at first live } \\
\text { birth (years) }\end{array}$ & $23.7(3.7)$ & $24.2(4.8)$ \\
\hline \multicolumn{3}{|l|}{ Parity (\%) } \\
\hline Nulliparous & 9.3 & 14.4 \\
\hline $1-2$ & 32.0 & 35.5 \\
\hline $3-4$ & 40.1 & 38.4 \\
\hline $5+$ & 18.6 & 11.7 \\
\hline Postmenopausal (\%) & 44.2 & 37.0 \\
\hline \multicolumn{3}{|l|}{ Cigarette smoking (\%) } \\
\hline Never smoked & 44.8 & 52.2 \\
\hline Former smoker & 25.0 & 26.0 \\
\hline Current smoker & 30.2 & 21.8 \\
\hline HRT use $(\% \text { ever })^{c}$ & 46.1 & 47.0 \\
\hline $\begin{array}{l}\text { Oral contraceptives use } \\
\text { (\% ever) }\end{array}$ & 51.7 & 58.1 \\
\hline
\end{tabular}

a BMI = body mass index. ${ }^{\mathrm{b}} \mathrm{Among}$ parous women only. ${ }^{\mathrm{C}} \mathrm{HRT}=$ hormone replacement therapy; results among postmenopausal women only. 
Table 2 Age-adjusted and multivariate-adjusted hazard ratios (HR) and 95\% confidence intervals (95\% Cl) for the association between lifestyle, reproductive, and hormonal factors and risk of incident renal cell cancer

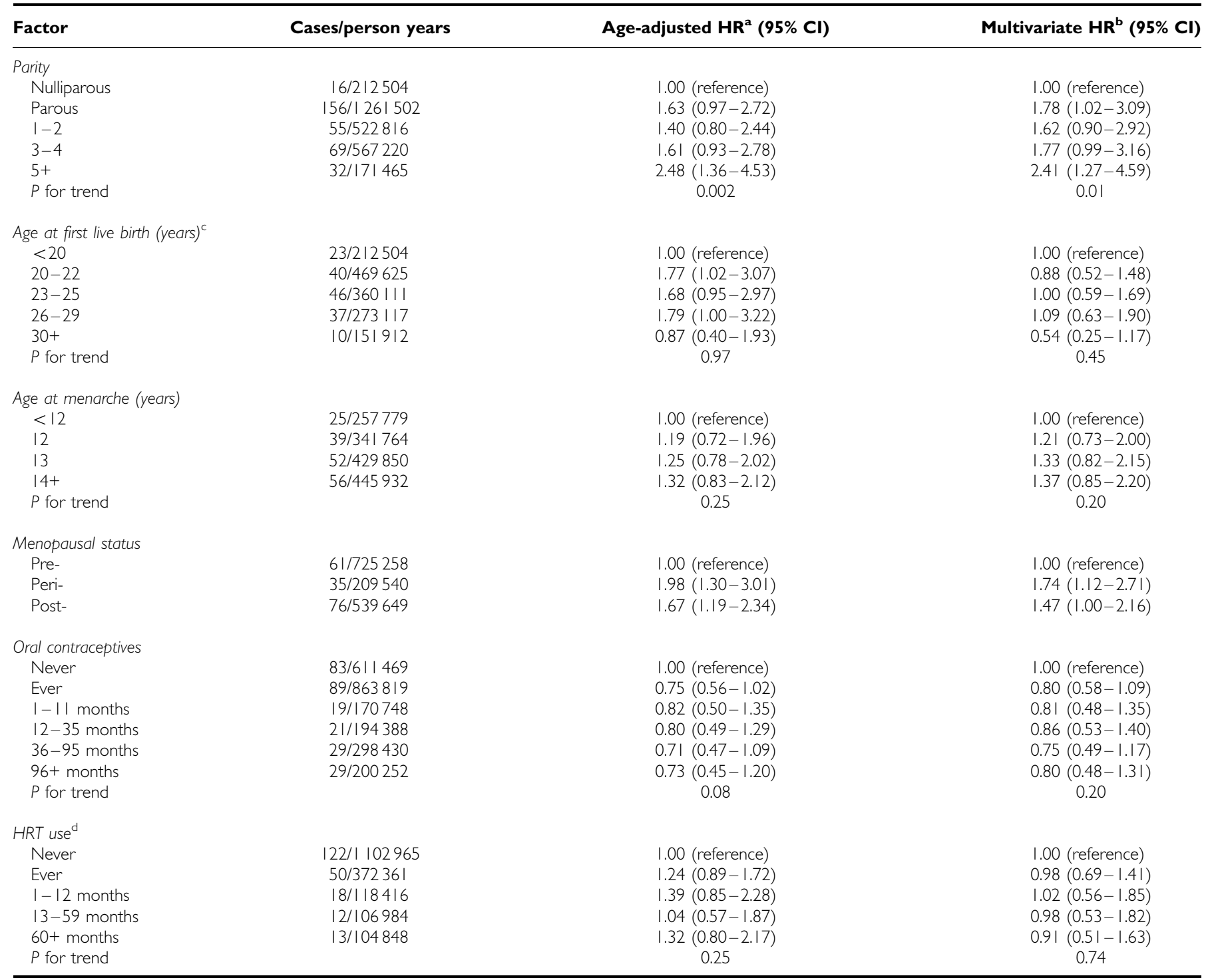

${ }^{a}$ Adjusted for age (time to event variable). ${ }^{b}$ Adjusted for age (time to event variable), pack-years (never smokers + five levels), body mass index (quintiles), menopausal status (pre-, peri-, postmenopausal), education (three levels), study centre, randomisation group (intervention vs control), and the other variables in the table. ${ }^{\mathrm{C}}$ Parous women only. 'Postmenopausal women only.

50-59 years at baseline, the HR associated with five or more pregnancies lasting $4+$ months was $3.43,95 \%$ CI $1.40-8.43, P$ for trend 0.009 , and a HR of $3.72,95 \%$ CI $1.35-10.24, P$ for trend 0.0006 was observed among never smokers. The association of parity with renal cell cancer did not differ by the level of BMI. The inverse association of oral contraceptive use with renal cell cancer was more pronounced among never smokers: HR $0.55,95 \% \mathrm{CI}$ $0.34-0.88$ ( $P$ for interaction 0.01 ). There was also a suggestion that the associations for oral contraceptive use were stronger in younger women (40-49 years old) and overweight women $\left(\mathrm{BMI} \geqslant 25.1 \mathrm{~kg} \mathrm{~m}^{-2}\right)$.

\section{DISCUSSION}

In the prospective study reported here, we found a statistically significant increased risk of renal cell cancer in women with increasing parity, which was comparable in strength to the associations with smoking and BMI. The association with parity was strongest in women who were older at enrolment and in never smokers. There was a suggestion of reduced risk with a relatively early age at menarche and with ever use of oral contraceptives, but these associations did not achieve statistical significance. Renal cell cancer risk was not associated with age at first live birth or use of HRT. Both smoking and BMI showed positive dose-response relationships with renal cancer risk in this cohort, in line with previous studies.

Most previous studies have examined only a limited number of reproductive factors, most commonly parity and age at first live birth. Of nine studies that provided data on parity, four found no association (Krieger et al, 1992; McCredie and Stewart, 1992; Mellemgaard et al, 1994; Gago-Dominguez et al, 1999), one showed a borderline positive association (Cantor et al, 1993), and four (including the two cohort studies) showed a significant positive association (Chow et al, 1995; Lindblad et al, 1995; Lambe et al, 2002; Nicodemus et al, 2004). Similar to these latter studies, we 
Table 3 Multivariate-adjusted hazard ratios (HR) and 95\% confidence intervals $(95 \% \mathrm{Cl})$ for the association between parity and oral contraceptive use and renal cell cancer, stratified by other risk factors

\begin{tabular}{|c|c|c|c|}
\hline Stratification variables & $\begin{array}{c}\mathbf{H R}^{\mathbf{a}} \\
(95 \% \mathrm{Cl})\end{array}$ & $\begin{array}{c}\mathbf{H R}^{\mathbf{a}} \\
(95 \% \mathrm{Cl})\end{array}$ & $\begin{array}{c}P \text { for } \\
\text { interaction }\end{array}$ \\
\hline Age at enrolment & $40-49$ years & $50-59$ years & \\
\hline \multicolumn{4}{|l|}{ Parity } \\
\hline Nulliparous & 1.00 (reference) & 1.00 (reference) & \\
\hline $1-2$ & $1.05(0.90-1.28)$ & $2.21(0.92-5.33)$ & \\
\hline $3-4$ & $1.15(0.53-2.48)$ & $2.28(0.96-5.41)$ & \\
\hline $5+$ & $0.97(0.32-2.96)$ & $3.43(1.40-8.43)$ & 0.11 \\
\hline$P$ trend & 0.86 & 0.009 & \\
\hline \multicolumn{4}{|l|}{ Oral contraceptive use } \\
\hline Never & 1.00 (reference) & 1.00 (reference) & \\
\hline Ever & $0.77(0.46-1.29)$ & $0.90(0.61-1.34)$ & 0.35 \\
\hline Smoking status & Never smokers & Ever smokers & \\
\hline \multicolumn{4}{|c|}{ 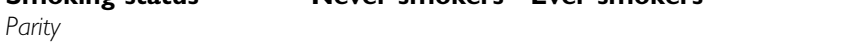 } \\
\hline Nulliparous & 1.00 (reference) & I.00 (reference) & \\
\hline $1-2$ & $1.40(0.5 \mid-3.84)$ & $1.46(0.73-2.95)$ & \\
\hline $3-4$ & $2.71(1.06-6.97)$ & $1.10(0.53-2.27)$ & \\
\hline $5+$ & $3.72(1.35-10.24)$ & $1.65(0.72-3.78)$ & $<0.005$ \\
\hline$P$ for trend & 0.0006 & 0.67 & \\
\hline \multicolumn{4}{|l|}{ Oral contraceptive use } \\
\hline Never & 1.00 (reference) & 1.00 (reference) & \\
\hline Ever & $0.55(0.34-0.88)$ & $0.97(0.64-1.49)$ & 0.01 \\
\hline Body mass index & $<25.1 \mathrm{~kg} \mathrm{~m}^{-2}$ & $>25.1 \mathrm{~kg} \mathrm{~m}^{-2}$ & \\
\hline \multicolumn{4}{|l|}{ Parity } \\
\hline Nulliparous & 1.00 (reference) & I.00 (reference) & \\
\hline $1-2$ & $1.34(0.63-2.86)$ & $1.45(0.7 \mid-3.65)$ & \\
\hline $3-4$ & $1.47(0.70-3.11)$ & $1.61(0.7 \mid-3.65)$ & \\
\hline $5+$ & $2.07(0.86-5.01)$ & $2.13(0.88-5.11)$ & 0.48 \\
\hline$P$ for trend & 0.12 & 0.09 & \\
\hline \multicolumn{4}{|l|}{ Oral contraceptive use } \\
\hline Never & 1.00 (reference) & 1.00 (reference) & \\
\hline Ever & $0.87(0.55-1.37)$ & $0.77(0.50-1.19)$ & 0.63 \\
\hline
\end{tabular}

${ }^{a}$ Adjusted for age (time to event variable), menopausal status (pre-, peri-, postmenopausal), education (three levels), study centre, randomisation group (intervention vs control), and the other variables in the table apart from those involved in a particular interaction.

found a significant positive dose-response relationship with increasing parity.

Findings regarding an association of age at first live birth have been weaker and less consistent. Two case-control studies indicated no association of age at first live birth with renal cell cancer (Cantor et al, 1993; Lindblad et al, 1995), whereas two other case-control studies suggested a borderline inverse association (Mellemgaard et al, 1994; Chow et al, 1995). The large cohort study by Lambe et al (2002) reported a significant inverse association, the $\mathrm{OR}$ in the highest quartile relative to that in the lowest being 0.89 (95\% CI $0.69-1.15), P$ for trend 0.04 , suggesting, at most, an association of relatively small magnitude. We found no clear evidence of a trend with age at first live birth, and the $40 \%$ reduction in risk among women who had their first live birth at 30 years or greater was based on only 10 cases.

Of the four studies (all case-control) presenting findings on age at menarche, two (McCredie and Stewart, 1992; Chow et al, 1995) showed no association, whereas the other two suggested that risk decreases with increasing age at menarche (Mellemgaard et al, 1994; Lindblad et al, 1995); however, neither the individual risk estimates nor the trends approached statistical significance. We found a nonsignificant increased risk with older age at menarche, although the trend was not statistically significant. Analysis of the large case-control study by Lindblad et al (1995) showed that, after careful adjustment for BMI, parity, and other factors, the inverse associations with age at first birth and age at menarche were attenuated.

Of four studies of oral contraceptive use (Mellemgaard et al, 1994; Chow et al, 1995; Lindblad et al, 1995; Gago-Dominguez et al, 1999), three showed some evidence of reduced risk among users, the other finding no association (Gago-Dominguez et al, 1999). Our results are suggestive of a $20 \%$ reduction in risk among ever users of oral contraceptives, although there was no trend with duration of use. In the analysis stratified by age at enrolment, a greater reduction in risk was seen in younger women. Findings concerning hormone replacement use have been inconsistent (Mellemgaard et al, 1994; Chow et al, 1995; Lindblad et al, 1995; Gago-Dominguez et al, 1999; Nicodemus et al, 2004). In keeping with two case-control studies (Lindblad et al, 1995; GagoDominguez et al, 1999), we found no evidence of an association with ever use or with duration of use.

Whereas smoking, obesity, and hypertension are established risk factors for renal cell cancer (Lindblad and Adami, 2002; McLaughlin et al, 2006), it is unclear whether reproductive or hormonal factors play a role. A number of findings support the concept that pregnancy-associated hormonal changes, and, particularly, high oestrogen levels, may promote malignant changes by stimulating renal cell proliferation either directly or via growth factors (Concolino et al, 1993). These findings include the fact that administration of potent oestrogens has been shown to induce renal cancers in the Syrian hamster (Kirkman, 1959; Reznik-Schuller, 1979; Li and Li, 1990; Cavalieri et al, 2001), the presence of oestrogen and progesterone receptors in normal and malignant renal cells (Concolino et al, 1976; Ronchi et al, 1984), and the observed association with obesity, which provides a major source of oestrogen in postmenopausal women. However, the evidence supporting a role of exposure to endogenous or exogenous oestrogens in renal cell carcinogenesis is conflicting. The association of factors such as age at menarche, age at menopause, parity, and exogenous oestrogen exposure with renal cell cancer presents a markedly different pattern from that seen for breast and endometrial cancer. The male predominance in incidence rates of the disease, the positive association with parity in some studies, and the observed reduction in risk in users of oral contraceptives in some studies suggest that exposure to endogenous oestrogens may be protective rather than a risk factor. Furthermore, the appropriateness of the Syrian hamster animal model to renal cell carcinoma in humans has been questioned (Gago-Dominguez et al, 2002).

The positive association with parity may reflect the association of normal pregnancies with hyperfiltration (Krutzen et al, 1992; Sturgiss et al, 1996). Based on animal studies, glomerular hyperfiltration may play a role in the development of glomerulosclerosis (Neuringer and Brenner, 1992; Westenend et al, 1992), which makes the nephrons more susceptible to exposure to carcinogens. Furthermore, pregnancy-associated weight gain could provide a partial explanation for the association of parity with renal cell cancer (Lambe et al, 2002).

Recently, an attempt has been made to provide a unified explanation of the aetiology of renal cell cancer based on the mechanism of lipid peroxidation (Gago-Dominguez et al, 2002). Gago-Dominguez et al noted that lipid peroxidation is increased among both obese and hypertensive subjects, and that in animal models lipid peroxidation of the proximal renal tubules has been shown to be a necessary condition for chemically induced renal carcinogenesis. The authors argued that lipid peroxidation may also explain the association of other risk factors, including cigarette smoking, the male preponderance of kidney cancer, parity, diabetes, and a protective effect of antioxidants, as there is evidence indicating that these risk factors are associated with increased lipid peroxidation, and that dietary antioxidants are 
associated with decreased lipid peroxidation. In keeping with this, pregnant women have been observed to have higher levels of serum lipid peroxide compared to nonpregnant women (GagoDominguez et al, 2002). Gago-Dominguez et al (2002) further point to Fe-NTA-induced renal carcinogenesis in rats and mice as providing an experimental model relevant to human renal cell cancer. Intraperitoneal injections of Fe-NTA in rodents induce necrosis of the proximal renal tubules and, subsequently, a high incidence $(60-92 \%)$ of renal cell carcinoma. This model appears to correspond to human renal cell carcinoma, given that the tumour incidence in male rats is twice as high as in female rats, and that the histology involves clear and granular cells.

Strengths of the present study include its prospective nature, the availability of information on a number of reproductive and hormonal factors as well as other risk factors, and the high level of follow-up over a period of 16 years. A number of limitations should also be noted. First, information was not available on several factors of interest, including history of hypertension, miscarriages and abortions, and the specific regimen of HRT.

\section{REFERENCES}

Benichou J, Chow W-H, McLaughlin JK, Mandel JS, Fraumeni Jr JF (1998) Population attributable risk of renal cell cancer in Minnesota. Am J Epidemiol 148: 424-430

Cantor KP, Lynch CF, Johnson D (1993) Reproductive factors and risk of brain, colon, and other malignancies in Iowa (United States). Cancer Causes Control 4: 505-511

Cavalieri EL, Kumar S, Todorovic R, Higginbotham S, Badawi AF, Rogan EG (2001) Imbalance of estrogen homeostasis in kidney and liver of hamsters treated with estradiol: implications for estrogen-induced initiation of renal tumors. Chem Res Toxicol 14: $1041-1050$

Chow WH, Devesa SS, Warren JL, Fraumeni Jr JF (1999) Rising incidence of renal cell cancer in the United States. JAMA 281: 1628-1631

Chow WH, McLaughlin JK, Mandel JS, Blot WJ, Niwa S, Fraumeni Jr JF (1995) Reproductive factors and the risk of renal cell cancer among women. Int J Cancer 60: 321-324

Concolino G, Lubrano C, Ombres M, Santonati A, Flammia GP, Silverio F (1993) Acquired cystic kidney disease: the hormonal hypothesis. Urology 41: $170-175$

Concolino G, Marocchi A, Concolino F, Sciarra F, Di Silverio F, Conti C (1976) Human kidney steroid receptors. J Steroid Biochem 7: 831-835

Gago-Dominguez M, Castelao JE, Yuan J-M, Ross RK, Yu MC (1999) Increased risk of renal cell carcinoma subsequent to hysterectomy. Cancer Epidemiol Biomarkers Prev 8: 999-1003

Gago-Dominguez M, Castelao JE, Yuan J-M, Ross RK, Yu MC (2002) Lipid peroxidation: a novel and unifying concept of the etiology of renal cell carcinoma (United States). Cancer Causes Control 13: 287-293

Katz DL, Zheng T, Holford TR, Flannery J (1994) Time trends in the incidence of renal carcinoma: analysis Connecticut tumor registry data, 1935 - 1989. Int J Cancer 58: 57-63

Kirkman H (1959) Estrogen-Induced Tumors of the Kidney in the Syrian Hamster. National Cancer Inst Monogr. No.1 US. Bethesda, MD: Department of Health, Education, and Welfare

Krieger N, Marrett LD, Dodds L, Hilditch S, Darlington GA (1992) Risk factors for renal cell carcinoma: results from a population-based casecontrol study. Cancer Causes Control 4: 101-110

Krutzen E, Olofsson P, Back SE, Nilsson-Ehle P (1992) Glomerular filtration rate in pregnancy: a study in normal subjects and in patients with hypertension, preeclampsia and diabetes. Scand J Clin Lab Invest 52: 387-392

Lambe M, Lindblad P, Wuu J, Remler R, Hsieh CC (2002) Pregnancy and risk of renal cell cancer: a population-based study in Sweden. Br J Cancer 86: $1425-1429$

Li JJ, Li SA (1990) Estrogen carcinogenesis in hamster tissues: a critical review. Endocr Rev 11: 524-531

Lindblad P, Adami HO (2002) Kidney cancer. In: Textbook of Cancer Epidemiology HO Adami, D Hunter, D Trichopolulos (eds) pp Oxford: Oxford University Press. 467-485
Second, only information collected at baseline was available, so that we were not able to take into account changes in the exposures of interest over the follow-up period. Nevertheless, we were able to detect monotonic dose-response relationships with smoking and $\mathrm{BMI}$, and our results regarding parity and oral contraceptive use are in agreement with the findings of the larger previous studies. It is unclear, however, whether changes in parity or in oral contraceptive use have contributed to the increasing rates of renal cell carcinoma in women.

\section{ACKNOWLEDGEMENTS}

This study was funded in part by the National Cancer Institute of Canada. We thank Statistics Canada, the provincial and territorial Registrars of Vital Statistics, and the Cancer Registry directors for their assistance in making the cancer incidence and mortality data available.
Lindblad P, Mellemgaard A, Schlehofer B, Adami H-O, McCredie M, McLaughlin JK, Mandel JS (1995) International renal-cell cancer study. V. Reproductive factors, gynecologic operations and exogenous hormones. Int J Cancer 61: $192-198$

McCredie M, Stewart JH (1992) Risk factors for kidney cancer in New South Wales, Australia. II. Urologic disease, hypertension, obesity, and hormonal factors. Cancer Causes Control 3: 323-331

McLaughlin JK, Lipworth L (2000) Epidemiologic aspects of renal cell cancer. Semin Oncol 27: 115-123

McLaughlin JK, Lipworth L, Tarone RE, Blot WJ (2006) Renal cancer. In: Cancer Epidemiology and Prevention Schottenfeld D, Fraumeni Jr JF (eds) 3rd edn, New York: Oxford University Press. 1087-1100

Mellemgaard A, Engholm G, McLaughlin JK, Olsen JH (1994) Risk factors for renal-cell carcinoma in Denmark. III. Role of weight, physical activity and reproductive factors. Int J Cancer 56: 66-71

Miller AB, Baines CJ, To T, Wall C (1992) Canadian national breast screening study. I. Breast cancer detection and death rates among women aged 40-49 years. II. Breast cancer detection and death rates among women aged 50-59 years. Canad Med Assoc J 147: 1459-1488

Neuringer JR, Brenner BM (1992) Glomerular hypertension: cause and consequence of renal injury. J Hypertens Suppl 10: S91 - S97

Nicodemus KK, Sweeney C, Folsom AR (2004) Evaluation of dietary, medical and lifestyle risk factors for incident kidney cancer in postmenopausal women. Int J Cancer 108: 115-121

Reznik-Schuller H (1979) Carcinogenic effects of diethylstilbestrol in male Syrian golden hamsters and European Hamsters. J Natl Cancer Inst 62: $1083-1088$

Rohan TE, Hartwick W, Miller AB, Kandel RA (1998) Immunohistochemical detection of c-erbB-2 and p-53 in benign breast disease and breast cancer risk. J Natl Cancer Inst 90: 1262-1269

Ronchi E, Pizzocaro G, Miodini P, Piva L, Slavioni R, Di Fronzo G (1984) Steroid hormone receptors in normal and malignant human renal tissue: relationship with progestin therapy. J Steroid Biochem 21: 329-335

Rothman KJ, Greenland S (1998) Modern Epidemiology. Philadelphia, PA: Lippincott-Raven

Siiteri PK (1987) Adipose tissue as a source of hormones. Am J Clin Nutr 45: $277-282$

Sturgiss SN, Wilkinson R, Davison JM (1996) Renal reserve during human pregnancy. Am J Physiol 271: F16-F20

Tate R, Iddenden R, Harnden P, Morris E, Craigs C, Bennett C, Brook C, Haward RA, Forman D (2003) Increased incidence of renal parenchymal carcinoma in the Northern Yorkshire region of England, 1978 - 1997. Eur J Cancer 39: 961 - 967

Vugrin D (1987) Biological aspects of renal cell carcinoma. Semin nephrol 7: $117-122$

Westenend PJ, Nooyen YA, van der Krogt JA, van Brummelen P, Weening JJ (1992) Functional and structural determinants of glomerulosclerosis in the fawn-hooded rat. Eur J Clin Invest 22: 391-395 